\title{
HYGROTHERMAL AGING EFFECTS ON MECHANICAL AND FATIGUE BEHAVIORS OF A SHORT- NATURAL-FIBER- REINFORCED COMPOSITE
}

\author{
M.Mejria $^{\mathrm{a}, \mathrm{b}}$, L.Toubal ${ }^{\mathrm{a}}$, J.C.Cuillière ${ }^{\mathrm{b}}$, V.François ${ }^{\mathrm{b}}$ \\ ${ }^{a}$ Laboratory of Mechanics and Eco-Materials (LMEM), Université du Québec à Trois-Rivières, 3351 boul. \\ Des Forges, C.P.500, G9A 5H7, Québec, Canada \\ ${ }^{\mathrm{b}}$ Équipe de Recherche en Intégration Cao-CAlcul (ERICCA), Université du Québec à Trois-Rivières, 3351 \\ boul. Des Forges, C.P.500, G9A 5H7, Québec, Canada
}

\begin{abstract}
A new natural fiber composite made of high density polyethylene (HDPE) and $40 \%$ wt of short birch fibers (SBF) was developed to replace polyamide (better known under its industrial name "Nylon") in spur gear manufacturing. The effect of hygrothermal aging on quasi-static and fatigue bending behaviors of this new composite has been studied in this work. Once hygrothermal aging is completed, flexural quasi-static tests have been performed on aged specimens and results compared with those obtained from unaged specimens. It has been observed that hygrothermal aging has no significant effect on flexural mechanical properties of this composite. After characterization, bending fatigue tests have been conducted on aged specimens and results have been compared with those of unaged specimens. These fatigue tests show that hygrothermal aging decreases the high cycles fatigue strength (HCFS) of this composite. The cause of this fatigue durability decrease has been investigated using Fourier transform infrared spectroscopy (FT-IR), thermogravimetric analysis (TGA) and a scanning electron microscope (SEM). These tests show that the chemical composition and thermal behavior of this composite are not affected by hygrothermal aging. On the contrary, these tests show that damage mechanisms of this composite (HDPE/40\%wt of SBF) are directly affected by this type of aging.
\end{abstract}

Keywords: hygrothermal aging, fatigue durability, residual strength, damage mechanisms, natural fiber composite 


\section{1) INTRODUCTION}

After decades of High-Tech development of synthetic fibers such as carbon, aramid and glass, several researchers were interested, these last years, to natural fibers as reinforcement. The scientific interest of using this type of fibers derives from many advantages that these fibers present over synthetic fibers: reasonable mechanical properties [1-4], low density, clearly positive environmental impact, economical production and processing and safe handling/working conditions. However, the development of natural fiber composites, especially short vegetal-based fibers composites, is still limited due to the lack of knowledge about the hydrophilic behavior of natural fibers and the effect of hygrothermal aging on the mechanical properties of natural-fiber-reinforced composites.

Several research projects have been realized on short vegetal fiber composites to understand the effect of hygrothermal aging on their mechanical properties. Based on the literature, two types of research work can be distinguished: research work based on exposing composites to relative humidity $(\mathrm{RH})$ and research work based on immersion of composites in distilled water. In the first type of research work, several papers have assessed the effect of hygrothermal aging ( $\mathrm{RH}$ coupling with temperature) on the quasi-static and impact behaviors of short vegetal fiber composites [5-9]. R.H.Hu et al.[5] have observed that, at a given $\mathrm{RH}$ rate and temperature, tensile strength and strain at failure of polylactide reinforced with short jute fibers decrease with an increase of the absorbed moisture content. Moreover, Scanning Electron Microscope (SEM) observations on tensile fractured surfaces have shown that fibers fracture and fibers debonding/pull out respectively are characteristic damage mechanisms at short and long term aging. M.Assarar et al.[8, 9] have worked on short hemp-fiber-reinforced polypropylene and on the influence of different environmental conditions on tensile mechanical properties of this material. These environmental conditions have been imposed to the composite by fixing the RH rate and by using different temperatures [8]. These authors have shown that an increase of temperature causes a decrease of Young modulus/tensile strength and an increase of strain at failure of this composite. Other authors have investigated the effect of RH values on the impact behavior of short vegetal fiber composites. A.K.Bledzki et al.[6] have fixed temperature and have shown that an increase of RH rate causes a decrease of Charpy impact strength and of the damping index of woodfiber-reinforced polypropylene. Concerning immersion of natural fiber composites in distilled water, several research teams have worked on the effect of water absorption on the quasi-static, impact and thermal behaviors of short vegetal fiber composites. Quasi-static behavior usually refers to tensile [10-20] and flexural $[15,19,20]$ quasi-static behaviors. It has been shown that an increase of water content in specimen causes a decrease of the quasi-static rigidity/strength and an increase of the tensile strain at failure of short vegetal fiber composites. Moreover, it has been observed that an increase of water immersion temperature can cause a drop of tensile and flexural mechanical properties. The influence of water uptake on the impact behavior of short vegetal fiber composites has been studied by several authors such as C.P.L.Chow et al. [12], J.J.Balatinecz et al. [15] and T.Yu et al. [20]. These authors have shown that impact strength increases with water uptake at low water content, reaches a maximum and decreases at higher water content. 
T.Yu et al.[20] have explained that, at short-term aging, or low water content, water uptake enhances chain mobility which causes an increase of impact strength and that, for long-term aging, or higher water content, this phenomenon disappears which makes that impact strength drops. Scanning Electron Microscope (SEM) and thermogravimetric analysis (TGA) results have also been shown in research papers to evaluate the effect of water absorption on damage mechanisms and on thermal stability. SEM $[10,12,13,20]$ has shown that presence of water in the composite induces new damage mechanisms such as debonding and pull out of fibers. TGA tests [10] show that water uptake causes a decrease of the thermal behavior of this type of composites. This decrease is characterized by a drop of temperatures associated with the sequence of decomposition stages along TGA tests.

Despite the amount of research work cited previously, the range of applications involving short vegetal fiber composites in engineering design is still limited due to a lack of knowledge about the effect of hygrothermal aging on long-term behavior of these composites. In this context, the influence of hygrothermal aging on the 3-point-flexural fatigue behavior of a new developed composite is assessed in this paper. The objective is replacing polyamide (commonly known as Nylon) in spur gears manufacturing with high density polyethylene (HDPE) reinforced with $40 \%$ wt (in weight) of short birch fibers (SBF). Indeed, using this type of composite for spur gears manufacturing may reduce manufacturing costs, from 5.5 can $\$ / \mathrm{kg}$ (for polyamide) to 1.6 can $\$ / \mathrm{kg}$ (for polyethylene) [21]. Moreover, using birch fibers may also reduce the use of oil-based plastic materials. The choice of the type and rate $(40 \% \mathrm{wt})$ of natural fibers is based on the significant presence of birch in Canada and on results obtained by Bravo et al. [22, 23] and Mejri et al. [24]. These authors have shown that using $40 \%$ wt of SBF, as reinforcement, allows obtaining quasi-static mechanical properties and bending fatigue behavior that are similar to those of plastic materials such as polyamide (PA6 and PA11).

This paper is structured as follows: in section 2, the material studied is first presented along with the process used for manufacturing bending specimens, which is followed by a presentation of the methodology applied in experimental testing. In section 3, results of hygrothermal aging are presented, at first, by plotting the evolution of water uptake and Young modulus with time along immersion. Then, bending quasi-static and fatigue results ( $\varepsilon$-n curve and residual strength evolutions) obtained from aged and unaged specimens are compared [24] to evaluate the effect of hygrothermal aging on the quasi-static and fatigue behaviors of the developed composite. Finally, several results obtained with Fourier Transform Infrared Spectroscopy (FT-IR), TGA and SEM, performed on unaged and aged specimens, are presented to understand why fatigue properties of this composite are affected by hygrothermal aging.

\section{2) EXPERIMENTAL TESTS}

\section{1) MATERIAL}

The thermoplastic used in this work is high density polyethylene (HDPE Sclair 2909, donated by NOVA Chemicals). Short wood fibers from white birch (TMP 20-60 mesh) and MAPE (maleated polyethylene, G2010) are respectively used as reinforcement and coupling agent to manufacture composite 
bending specimens [24]. The coupling agent is used to improve the quality of interface between HDPE and short birch fibers (SBF).

\section{2) SAMPLES MANUFACTURING AND SELECTION}

The process used for manufacturing these bending specimens involved two consecutive steps, which are blending and molding [24]. Blending consists in melting polyethylene with the coupling agent on rollers at temperature between 170 and $190{ }^{\circ} \mathrm{C}$ and mixing with fibers. When blending is completed, a composite sheet is removed from the roller and cut into strips (using a knife) with respect to the mold size. The second step is molding, which consists in filling a mold with material and putting it in a thermopress at $170^{\circ} \mathrm{C}$ and at a pressure of 10 to 15 metric tons. After 10 to 15 minutes of thermic compression, the mold is cooled to $60^{\circ} \mathrm{C}$, by circulating cold water at a constant $43^{\circ} \mathrm{C} \cdot \mathrm{min}^{-1}$ cooling rate. Bending specimens were manufactured using 40\%wt (in weight) of short birch fibers (SBF), 3\% of MAPE and 57\% of HDPE, according to dimensions and geometry as specified in ASTM-D638 and ASTM-D790 standards [24]. Dimensions of cavities in the mold used for manufacturing these samples are $127 \mathrm{~mm}$ (length), $12.5 \mathrm{~mm}$ (width) and $3.3 \mathrm{~mm}$ (thickness).

After manufacturing these samples, a selection step was performed to ensure that the fiber rate is as constant as possible among all samples used. This selection step is based on measuring Young's modulus of all specimens with an acoustic impulse device: specimens for which Young's modulus deviation, with respect to mean Young's modulus found by Bravo et al. [22], is higher than 7\% have been discarded. This selection step has been followed by X-ray micro computed tomography measurements [25] performed on selected specimen before hygrothermal aging. The aim of tomography measurement is detecting the presence of voids and assessing geometry and density of these voids. As shown in Figure 1, surfaces obtained from tomography measurements have been presented in $\mathrm{x}, \mathrm{y}$ and $\mathrm{z}$ directions to better represent characteristics of bending specimens before aging. Tomography planes used have been randomly chosen and results show the presence of fibers in light grey and matrix material in dark grey. Red ellipses used in Figure 1 illustrate voids caused by the manufacturing process used. Results presented in Figure 1 show that these voids present a low density and a circular section. 
a)

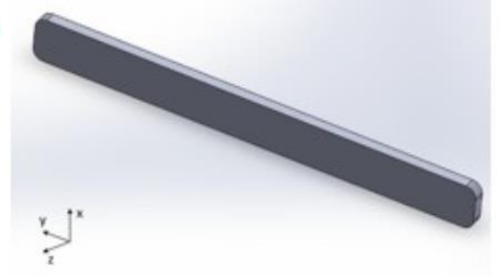

d)

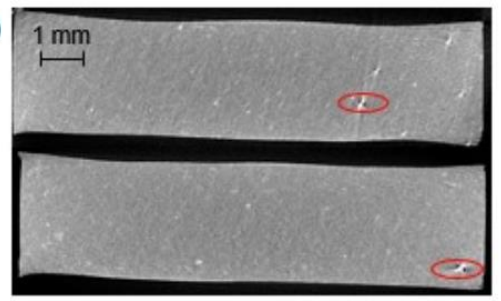

b)

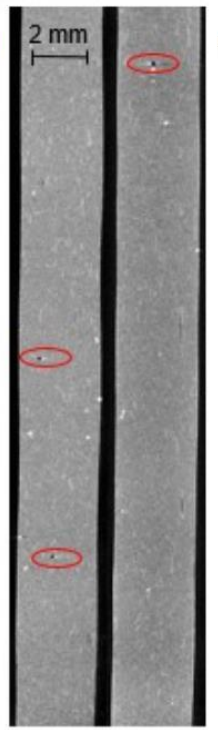

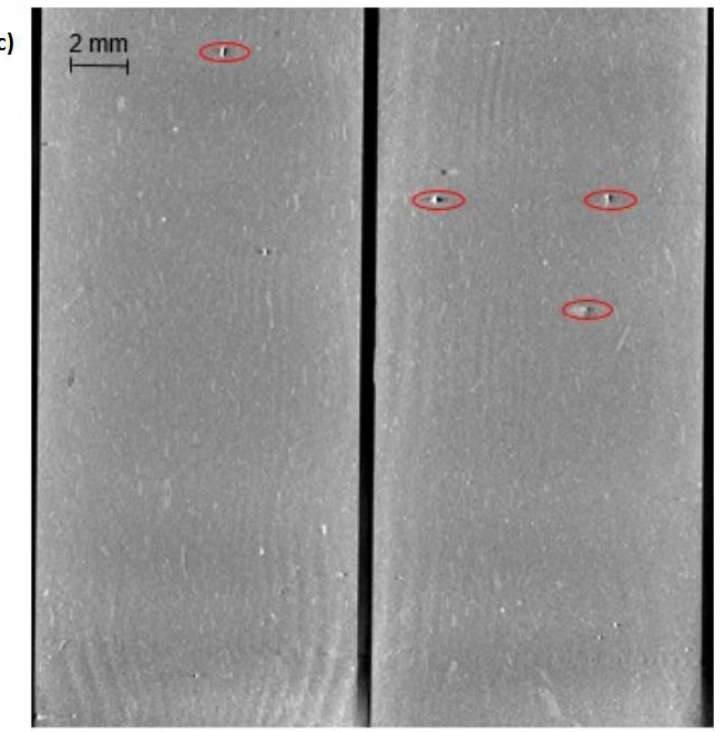

Figure 1: X-ray tomography of an unaged bending specimen made of HDPE and 40\%wt of SBF: a) CAD model of bending specimen; b) two scans in $(y, z)$ plane; $c)$ two scans in $(x, y)$ plane; d) two scans in $(x, z)$ plane

\section{3) HYGROTHERMAL AGING TESTS}

Hygrothermal aging tests were conducted by immersing bending specimens, after selection, in distilled water at $60^{\circ} \mathrm{C}$ (Figure 2a). This temperature has been chosen low enough to avoid thermal damage of the composite and high enough to reach saturation in a reasonable time. Every 48 hours, water uptake and tensile modulus of specimens have been measured. Water uptake has been assessed by measuring the weight of immersed specimens, using an electronic precision balance with $10^{-3} \mathrm{~g}$ accuracy. Water uptake is calculated using:

$M_{t}(\%)=\frac{W_{t}-W_{0}}{W_{0}} \times 100 \quad$ Eq. 1

Where:

$W_{t}$ : specimen weight at current time

$W_{0}$ : specimen weight at initial time (before the water uptake).

$M_{t}$ : Water uptake at current time

Tensile modulus E, has been assessed using an acoustic impulse device [26, 27]. This device applies an impulse excitation to a specimen, which is generated by automated tapping. The vibration induced is then recorded by a microphone and analyzed using the "Resonant Frequency \& Damping Analyzer (RFDA)" software from IMCE. Vibration analysis allows the determination of resonant frequency. Tensile modulus E is finally calculated from this frequency, according to the ASTM-E1876-09 standard.

Once immersed specimens reached water saturation, they were placed in an MTS environmental chamber (Figure $2 \mathrm{~b}$ ), at $65^{\circ} \mathrm{C}$, until almost recovering their initial weight. Water absorption was followed by drying to ensure that the moisture content in specimens is only due to ambient environmental conditions and that it 
remains constant along fatigue tests. Therefore, in this paper, hygrothermal aging is based on two steps (water absorption and drying).
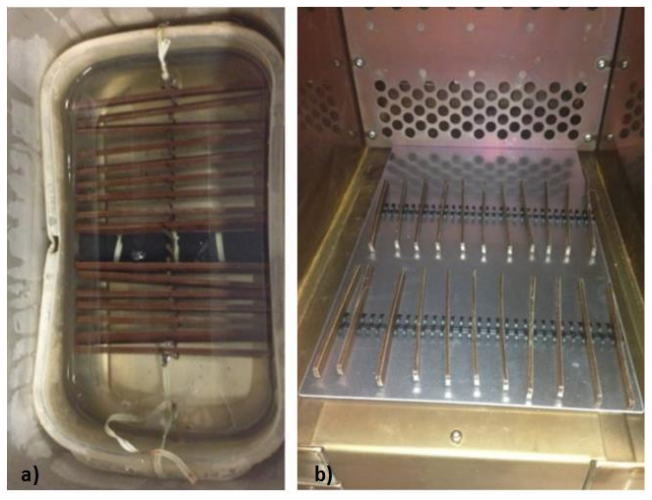

Figure 2: Hygrothermal aging of specimens a) Location of bending specimens in the thermal bath; b) Location of bending specimens in the MTS environmental chamber

\section{4) QUASI-STATIC BENDING TESTS}

Three-point flexural quasi-static tests were then performed on these aged specimens in accordance with the ASTM-D790 standard. These tests were carried out on an Instron model LM-U150 electromechanical testing machine, equipped with a $10 \mathrm{kN}$ load cell [24]. The parameters used for these tests were $1 \mathrm{~mm} / \mathrm{min}$ speed and $55 \mathrm{~mm}$ distance between flexural supports. The aim of these quasi-static bending tests was assessing the effect of hygrothermal aging on quasi-static mechanical properties of HDPE reinforced with $40 \%$ wt of SBF. This assessment was performed by comparing mechanical properties of aged specimens with those found for unaged specimens as presented in a previous work [24].

\section{5) BENDING FATIGUE TESTS}

After quasi-static tests, three-point flexural fatigue tests were conducted on aged specimens using a MTS servo hydraulic testing machine equipped with a $100 \mathrm{KN}$ load cell (Figure 3). They were performed using sinusoidal displacement control at a $10 \mathrm{~Hz}$ loading frequency. The displacement ratio $\left(R=\frac{\delta_{\min }}{\delta_{\max }}\right)$ was 0 for these tests. The objective of these tests was studying the fatigue behavior of aged HDPE reinforced with $40 \%$ wt of SBF and assessing the influence of hygrothermal aging on the fatigue behavior of this natural fiber composite. The effect of hygrothermal aging on durability and residual strength has been assessed by comparing results shown below with others presented in a previous paper for unaged specimens [24]. Six displacement levels were used with three samples for each displacement level, as specified by the ASTM-D7774 standard. Among all these six displacement levels, five were identical to those used for unaged specimens in a previous work [24]. The choice of these displacement levels will allow us to easily evaluate the effect of hygrothermal aging on the durability of HDPE reinforced with $40 \%$ wt of SBF. 
A CCD camera (Figure 3) was used along fatigue tests on these aged specimens. This camera was focused on the middle of the transverse surface of bending specimens [24]. Pictures were captured every $50 \mathrm{~s}$ along short fatigue tests and every $500 \mathrm{~s}$ along longer fatigue tests to avoid saturating the computer used for CCD camera acquisition. The objective of using this CCD camera is following the evolution and length of macro-cracks across the thickness of specimens. The detection of the maximum macro-crack length allows accurately evaluating the number of cycles to failure, which is referred to as fatigue life $\mathrm{N}_{\mathrm{f}}$.

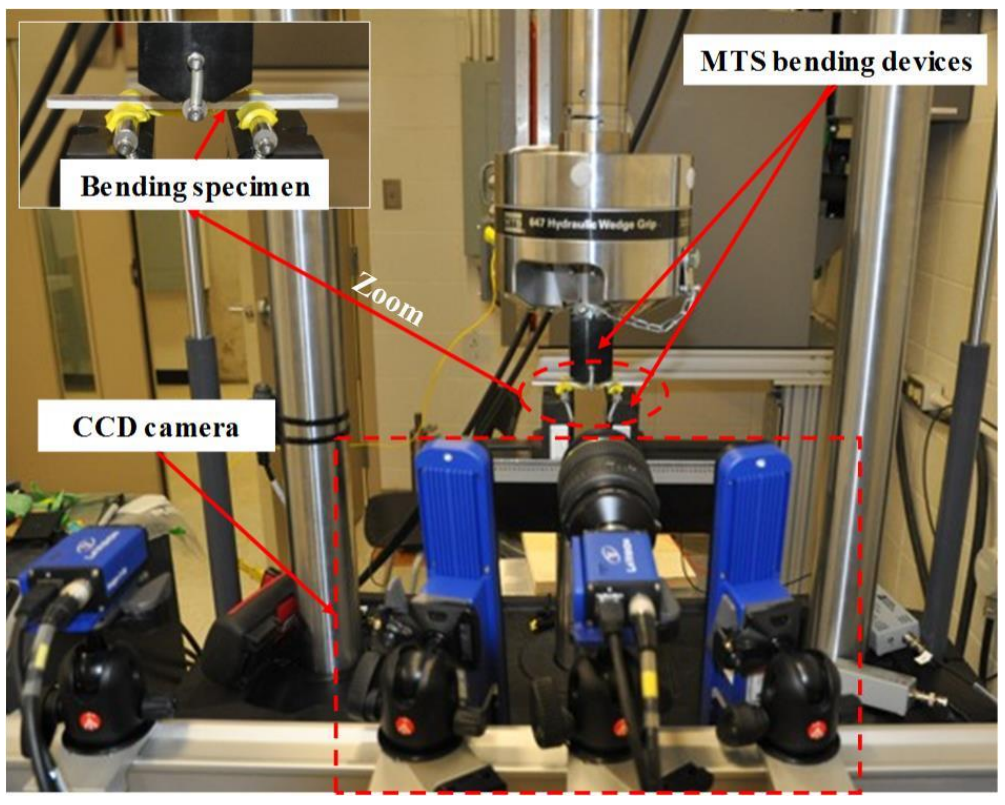

Figure 3: MTS fatigue machine setup with a CCD camera

\section{6) FTIR AND TGA TESTS}

Fourier transform infrared spectroscopy (FT-IR) was performed with a Perkin Elmer System 2000 spectrometer using a continuous dry air scanning technique at ambient temperature. For each specimen, the mean spectrum was recorded from 8 scans between 600 and $4000 \mathrm{~cm}^{-1}$ using a $2 \mathrm{~cm}^{-1}$ resolution. Moreover, thermogravimetric analysis (TGA) was conducted using a Pyris Diamond machine from Perkin Elmer. At first, the composite has been heated at $50^{\circ} \mathrm{C}$ for 15 minutes to eliminate moisture. Then, the material has been heated from $50^{\circ} \mathrm{C}$ to $575^{\circ} \mathrm{C}$ using a $5^{\circ} \mathrm{C} \cdot \mathrm{min}^{-1}$ heating speed and inert atmosphere (nitrogen gas). Finally, the composite has been heated from $575^{\circ} \mathrm{C}$ to $600^{\circ} \mathrm{C}$ using a $10^{\circ} \mathrm{C} \cdot \mathrm{min}^{-1}$ heating speed and air atmosphere. The evolution of the weight has been recorded along these two last steps.

FT-IR and TGA tests have been performed on unaged and aged birch-fiber-reinforced polyethylene. The aim of these FT-IR and TGA tests was to evaluate the effect of hygrothermal aging on the chemical composition and thermal behavior of this composite.

\section{7) SCANNING ELECTRON MICROSCOPE}


A scanning electron microscope (SEM) has been used to observe the fractured surface of bending specimens after fatigue tests. These observations have been made on aged and unaged specimens to detect the effect of hygrothermal aging on damage mechanisms involved. Micrographs were obtained with a JEOL JSM T300 microscope operated in secondary electron mode. The beam current and accelerating voltage were respectively $100 \mu \mathrm{A}$ and $15 \mathrm{kV}$.

\section{3) RESULTS AND DISCUSSION}

\section{1) HYGROTHERMAL AGING TESTS}

Figure 4a shows that all immersed specimens have reached saturation. The mean water uptake at saturation is $9.95 \%$. As shown in Figure 4a, the evolution of water uptake according to the square root of time presents a non-linear increase. This non-linear increase means that water diffusion in HDPE reinforced with $40 \%$ wt of SBF is non-Fickian. Moreover, it is worth noting that there is no significant difference in water uptake at saturation between these specimens. Indeed standard deviation of water uptake at saturation is only 0.1 , which can be explained by the fact that specimens used have been selected, as described in section 2.2, to ensure that fiber content is as constant as possible among all specimens.

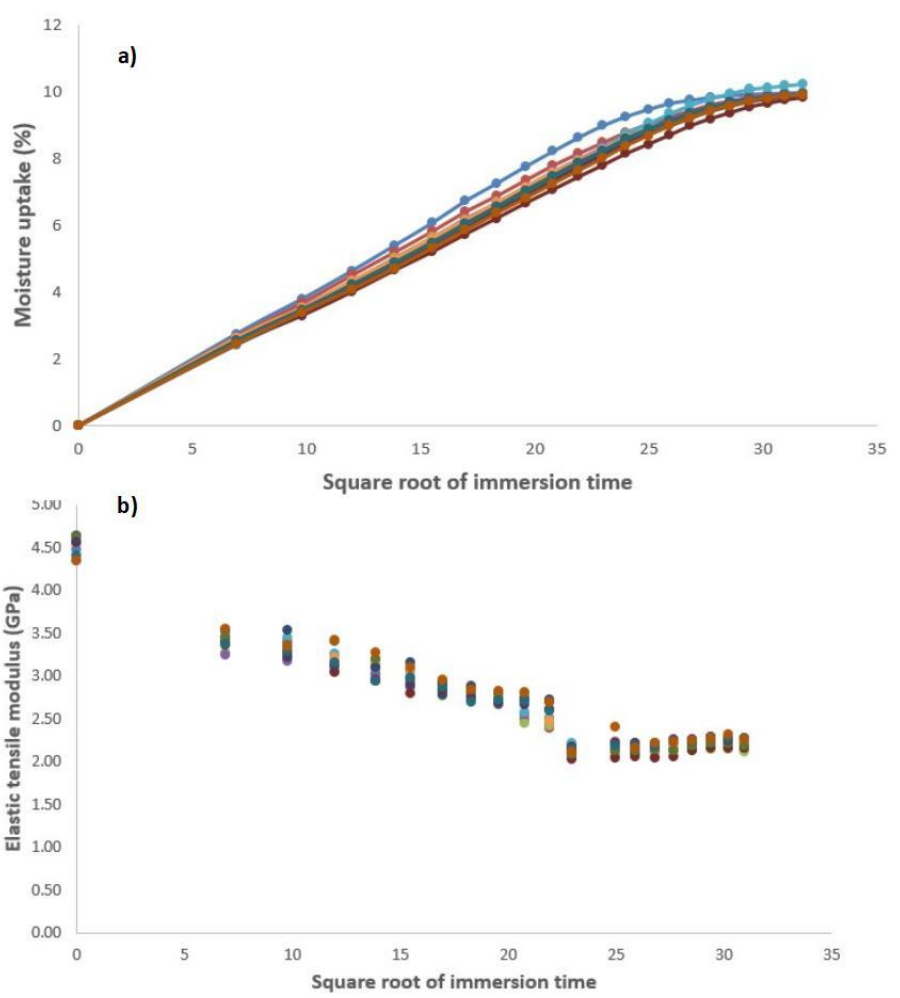

Figure 4: a) Water uptake of immersed specimens versus square root of immersion time; b) Elastic tensile modulus of immersed specimens versus square root of immersion time 
As mentioned in section 2.3, the evolution of the tensile modulus of immersed specimens along water uptake has been measured using an acoustic impulse device. The aim of this measurement is to evaluate the effect of water uptake on the tensile stiffness of this composite. Figure $4 \mathrm{~b}$ presents the evolution of tensile modulus with the square root of immersion time. It shows that, during the water absorption step, the mean tensile modulus of immersed specimens decreases drastically from $4.53 \mathrm{GPa}$ to 2.21 GPa at saturation. This drop of the mean tensile modulus, which is around $51.21 \%$ (if compared to the initial tensile modulus) is due to the swelling of birch fibers along water absorption.

Once saturation is reached for all immersed specimens, a large number of these specimens have been dried for 40 days to eliminate the absorbed water. Once dried, these samples are considered as aged samples. The remaining part of saturated specimens are not dried and are considered as wet specimens. These so called wet specimens have been directly used in quasi-static flexural tests to evaluate the effect of water uptake on quasi-static flexural properties of our composite.

\section{2) QUASI-STATIC BENDING TESTS}

Figure 5 presents stress-strain evolutions recorded along quasi-static flexural tests made on aged and wet specimens, as introduced just above. These curves are superposed with curves presented in a previous paper for unaged specimens [24]. As shown in Figure 5, the presence of water in specimens causes an important decrease of flexural elastic modulus and maximum stress. If compared with the mechanical properties of unaged specimens [24], the decrease of flexural elastic modulus is around $47.24 \%$ and the decrease of maximum stress is around 50.81\%. This important drop of flexural mechanical properties can be related to the swelling of birch fibers after water uptake. Moreover, the presence of water in wet specimens induces an increase of maximum strain. Indeed, after water saturation, the mean strain at failure is $58.07 \%$ higher than that found with unaged specimens.

Aged specimens present a 2.51 GPa mean flexural elastic modulus, a 54.10 MPa mean maximum stress and $5.98 \%$ mean strain at failure. These values respectively represent $98.82 \%, 96.28 \%$ and $96.45 \%$ of those found with unaged specimens [24]. Based on these results, we can conclude that there is no significant effect of hygrothermal aging on the flexural mechanical properties of HDPE reinforced with $40 \%$ wt of short birch fibers. This also means that drying specimens allowed removing the great majority of water from fibers and that drying allowed almost recovering quasi-static mechanical properties of unaged specimens. After hygrothermal aging, the behavior of this composite is still almost brittle. This behavior is characterized by a linear elastic domain, a nonlinear viscoelastic domain and a short plastic plateau (see Figure 5). Results obtained from quasi-static bending tests performed on unaged and aged specimens are summarized in Table 1. 


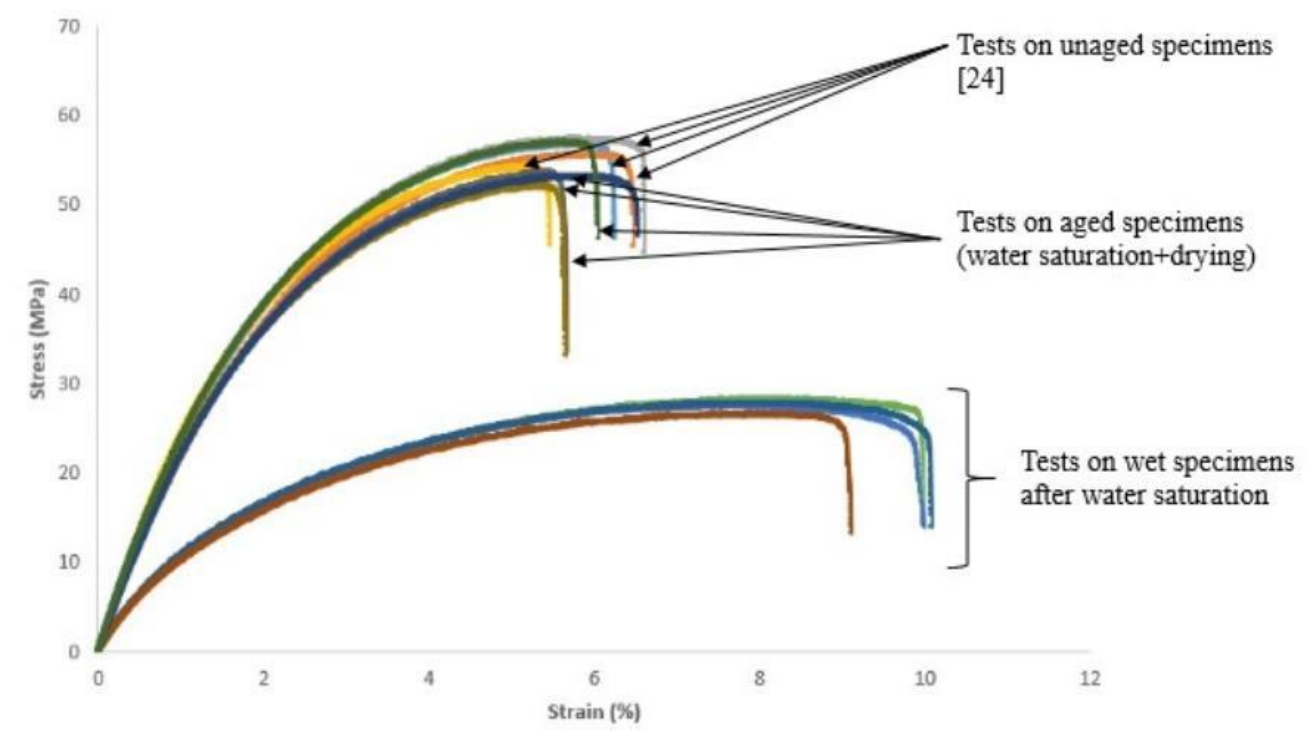

Figure 5: Bending stress-strain curves of aged HDPE $/ 40 \%$ wt of SBF superposed with results obtained with wet and unaged specimens [24]

Table 1: Bending mechanical properties of unaged and aged specimens made of HDPE/40\%wt of SBF

\begin{tabular}{cccc}
\hline $\begin{array}{c}\text { Mechanical } \\
\text { properties }\end{array}$ & Specimens & Unaged [24] & Aged \\
\hline Elastic modulus & $\mathbf{1}$ & 2.64 & 2.42 \\
(GPa) & $\mathbf{2}$ & 2.35 & 2.55 \\
& $\mathbf{3}$ & 2.51 & 2.38 \\
& $\mathbf{4}$ & 2.68 & 2.69 \\
& Mean value & 2.54 & 2.51 \\
& STD DEV & 0.15 & 0.14 \\
& Cov & 0.06 & 0.06 \\
Maximum stress & & & \\
(MPa) & $\mathbf{1}$ & 56.98 & 53.73 \\
& $\mathbf{2}$ & 55.80 & 52.26 \\
& $\mathbf{3}$ & 57.59 & 53.27 \\
& $\mathbf{4}$ & 54.38 & 57.14 \\
& Mean value & 56.19 & 54.10 \\
& STD DEV & 1.42 & 2.12 \\
& Cov & 0.03 & 0.04
\end{tabular}


Strain at failure

(\%)

\begin{tabular}{cll}
$\mathbf{1}$ & 6.25 & 5.68 \\
$\mathbf{2}$ & 6.48 & 5.66 \\
$\mathbf{3}$ & 6.61 & 6.53 \\
$\mathbf{4}$ & 5.47 & 6.05 \\
Mean value & 6.20 & 5.98 \\
STD DEV & 0.51 & 0.41 \\
Cov & 0.08 & 0.07 \\
\hline
\end{tabular}

\section{3) BENDING FATIGUE TESTS}

\subsection{1) DURABILITY OF MATERIAL}

Based on similar work found in the literature about other types of materials [28, 29], the fatigue durability of our composite has been characterized by determining the fatigue life of this material at different strain levels. Figure 6a illustrates the $\varepsilon-\mathrm{N}$ curve of our composite (HDPE reinforced with $40 \% \mathrm{wt}$ of short birch fibers) after aging. As introduced earlier, this curve corresponds to a $10 \mathrm{~Hz}$ loading frequency. In Figure 6a, this $\varepsilon-\mathrm{N}$ curve is compared with that representing the fatigue life of unaged specimens, at the same frequency $(10 \mathrm{~Hz})$, as presented in a previous work [24] . The aim of comparing these two $\varepsilon-\mathrm{N}$ curves is to evaluate the effect of hygrothermal aging on the high cycles fatigue strength (HCFS) of our composite. Strain levels presented in Figure $6 \mathrm{a}$ and Figure $6 \mathrm{~b}$ have been calculated using the following formula, as mentioned in the ASTM D-7264 standard:

$\varepsilon=\frac{6 \delta h}{L^{2}} \quad$ Eq. 2

Where

$\varepsilon:$ maximum strain at the outer surface

$\delta$ : displacement level ( $\mathrm{mm}$ )

h: thickness of specimen ( $\mathrm{mm}$ )

L: support span ( $\mathrm{mm})$

The arrows in Figure 6a indicate that the associated bending specimens were not broken when reaching the maximum number of fatigue cycles, which has been set at 5 million cycles in these fatigue tests. Based on the $\varepsilon-\mathrm{N}$ curve of aged specimens, we can state that HCFS is reached at a $0.78 \%$ strain level, which means that HCFS is reached at a $1.2 \mathrm{~mm}$ displacement level. If this result is compared with that obtained for unaged specimens (HCFS reached at a $0.91 \%$ strain level or at a $1.4 \mathrm{~mm}$ displacement level) [24]), we can conclude that hygrothermal aging results in a decrease of the HCFS of this composite. This decrease in the HCFS strain level is around $14.3 \%$ if compared to that found with unaged specimens. 
a)

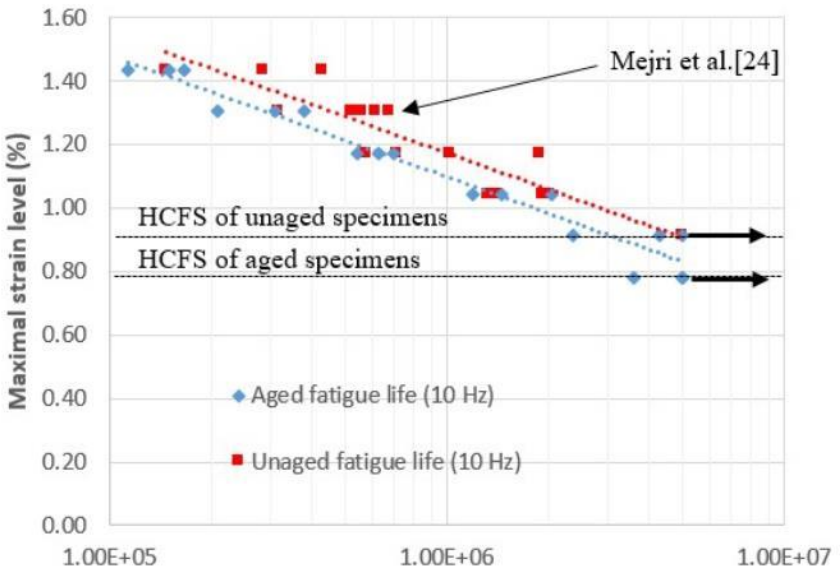

b)

Number of cycles to failure

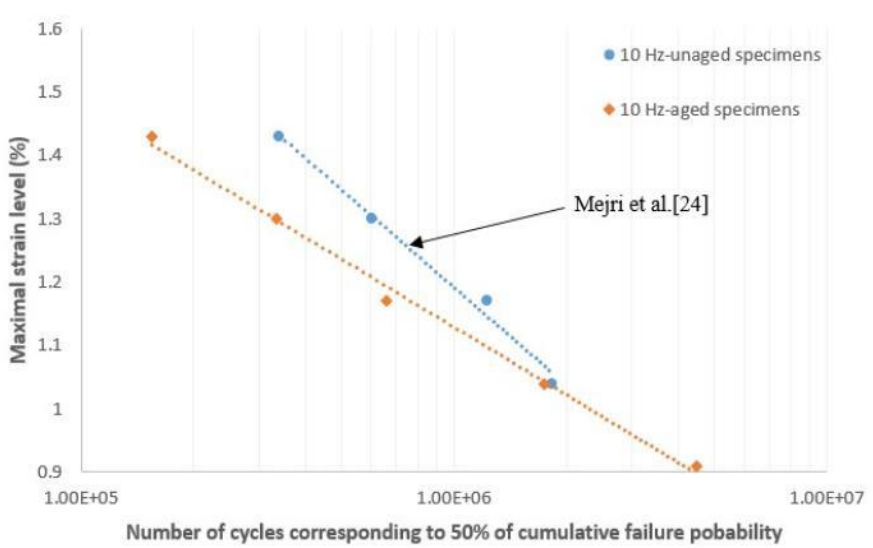

Figure 6: Fatigue durability of aged and unaged [24] HDPE reinforced with $40 \%$ wt of SBF: a) $\varepsilon-\mathrm{N}$ curves; b) Evolutions of characteristic life with the strain level applied

Once the $\varepsilon-\mathrm{N}$ curve of our composite obtained, a Weibull statistics analysis has been performed using the 2-parameter Weibull distribution [24]. This analysis allows determining the number of cycles that corresponds to $50 \%$ of cumulative failure probability $\left(\mathrm{N}_{0}\right) . \mathrm{N}_{0}$, referred to as characteristic life, represents one of the two parameters of the Weibull distribution. Figure $6 \mathrm{~b}$ presents the evolution of $\mathrm{N}_{0}$ with the applied strain level. In this figure, the evolution of $\mathrm{N}_{0}$ for aged specimens has been superposed with that obtained with unaged specimens [24] to evaluate the effect of hygrothermal aging on the characteristic life of this composite. For strain levels between 1.04\% and 1.43\% (which corresponds to displacement levels between $1.6 \mathrm{~mm}$ and $2.2 \mathrm{~mm}$ ), hygrothermal aging causes a decrease of the number of cycles that corresponds to $50 \%$ of cumulative failure probability. The gap between the trends of characteristic life for unaged versus aged specimens increases with the stain level applied.

Results in Figure $6 \mathrm{~b}$ have been obtained using strain levels that cause the failure of specimens before reaching the maximum number of fatigue cycles ( 5 million cycles as introduced above). As previously mentioned, the HCFS of unaged specimens has been reached at a $0.91 \%$ strain level (1.4 mm displacement level) while that of aged specimens has been reached at $0.78 \%$ strain level (1.2 mm displacement level). Consequently, the characteristic life curve associated with unaged specimens does not feature a point at a $0.91 \%$ strain level. 


\subsection{2) FATIGUE DAMAGE}

Fatigue damage of our composite (HDPE reinforced with $40 \%$ wt of short birch fibers) has been assessed by determining the evolution of residual strength with the number of fatigue cycles. After each fatigue test, the MTS data file has been processed with MATLAB to extract maximum displacement and maximum load for each fatigue cycle. Residual strength can then be calculated using the following formula, as specified by the ASTM D-7264 standard:

$\sigma=\frac{3 P L}{2 b h^{2}} \quad E q .3$

Where:

$\sigma:$ maximum stress (residual strength) at the outer surface at mid-span (MPa)

P: maximum load applied $(N)$

L: support span $(\mathrm{mm})$

b: width of specimen ( $\mathrm{mm})$

h: thickness of specimen (mm)

Figure 7 presents the evolution of residual strength for aged specimens at two strain levels. The choice of $1.17 \%$ and $0.78 \%$ strain levels $(1.8 \mathrm{~mm}$ and $1.2 \mathrm{~mm}$ displacement levels $)$ has been made to have both broken and unbroken specimens before reaching the maximum number of cycles. Figure 7 a presents the evolution of residual strength along fatigue cycles for aged specimens at a $1.17 \%$ strain level $(1.8 \mathrm{~mm}$ displacement level). These results show that the evolution of residual strength features three stages: rapid decline, gradual reduction and accelerated decline. The same three stages residual strength behavior as that found at a $1.17 \%$ strain level has been observed at other strain levels $(0.91 \%, 1.04 \%, 1.30 \%$ and $1.43 \%)$, which is not the case at a $0.78 \%$ strain level, as explained just below.

Residual strength curves shown in Figure $7 \mathrm{~b}$ have been obtained at a $0.78 \%$ strain level $(1.2 \mathrm{~mm}$ displacement level). For three curves among the four curves presented in Figure $7 \mathrm{~b}$, the evolution of residual strength only features two stages (rapid decline and gradual reduction). The fourth curve presented in Figure $7 \mathrm{~b}$ features three stages as for curves presented in Figure 7a. The difference between this fourth curve and the three other curves presented in Figure $7 \mathrm{~b}$ can be explained by a slight difference in fiber rate and fiber distribution inside this sample if compared with the three others. Indeed, even if specimens are selected, it remains that fiber rates and distributions are not exactly the same between two specimens. Thus, a slightly lower fiber rate inside a specimen may cause its failure before $5 \mathrm{E}+06$ cycles, which happens for the specimen associated with the fourth curve in Figure $7 \mathrm{~b}$. 
Based on results shown in Figure $7 \mathrm{a}$ and Figure $7 \mathrm{~b}$, we can conclude that the third stage obtained at a $1.17 \%$ strain level is caused by the initiation and propagation of macro-cracks in the specimens.

a)

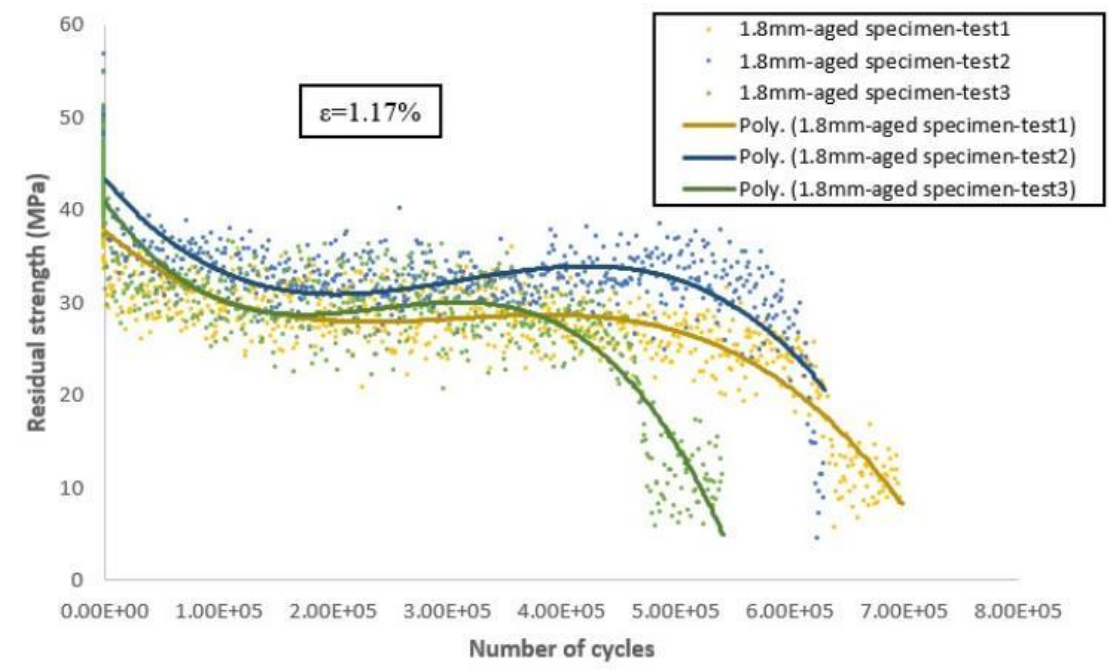

b)

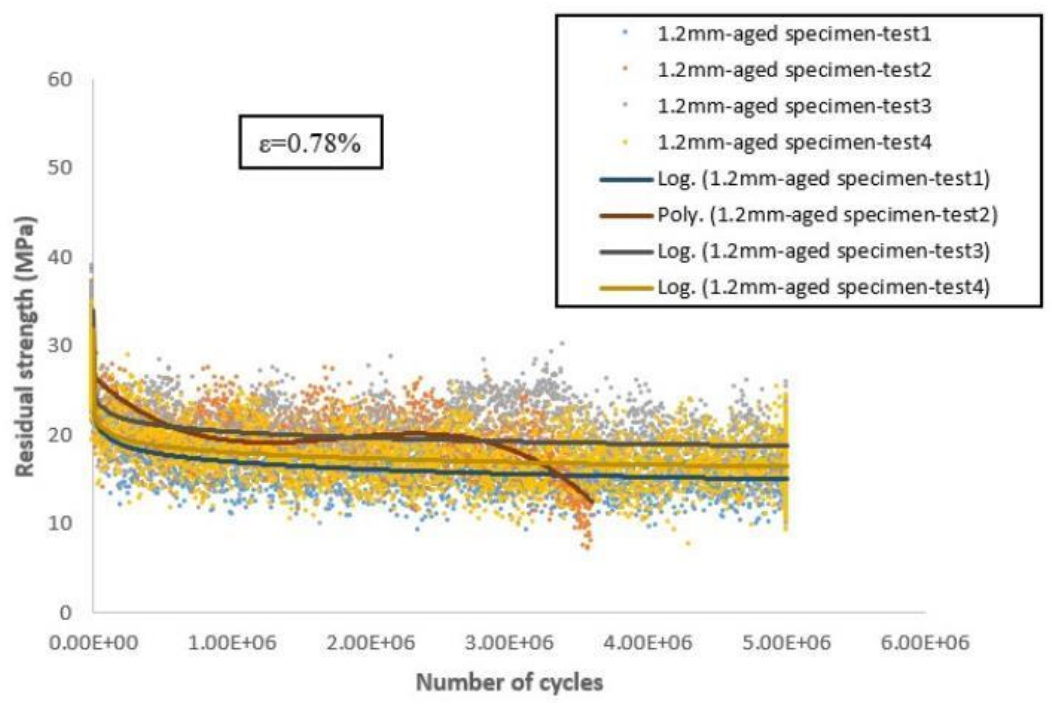

Figure 7: Evolution of residual strength of aged specimens versus the number of fatigue cycles: a) At a $1.17 \%$ strain level (1.8 $\mathrm{mm}$ displacement level); b) At a $0.78 \%$ strain level (1.2 $\mathrm{mm}$ displacement level)

From results presented in Figure 7 and from residual strength results obtained at other strain levels, we observe that residual strength can be considered as constant along the second stage (gradual reduction) due to its low variation along this stage. Moreover, it can be noticed that the gradual reduction stage represents more than $50 \%$ of these fatigue tests at any strain level. Based on that, the mean value of flexural stress in the second stage (referred to as second stage mean residual strength) has been evaluated for these tests. Figure 8 presents a comparison between second stage mean residual strength results obtained and quasi-static bending curve for aged specimen. From results presented in Figure 8, we can conclude that the second stage mean residual strength increases with the strain level applied. Moreover, the evolution of this second stage mean residual strength is similar to that of flexural stress along quasi-static 
bending test. Therefore, for more than $50 \%$ of cycles along fatigue tests, controlling strain can be considered as equivalent to controlling load. The stress level of equivalent load control is then determined from the second stage mean residual strength. As shown in Figure 8, these results have also been superposed with those found in a previous work [24] for unaged specimens. This comparison illustrates that hygrothermal aging has no significant effect on the evolution of second stage mean residual strength.

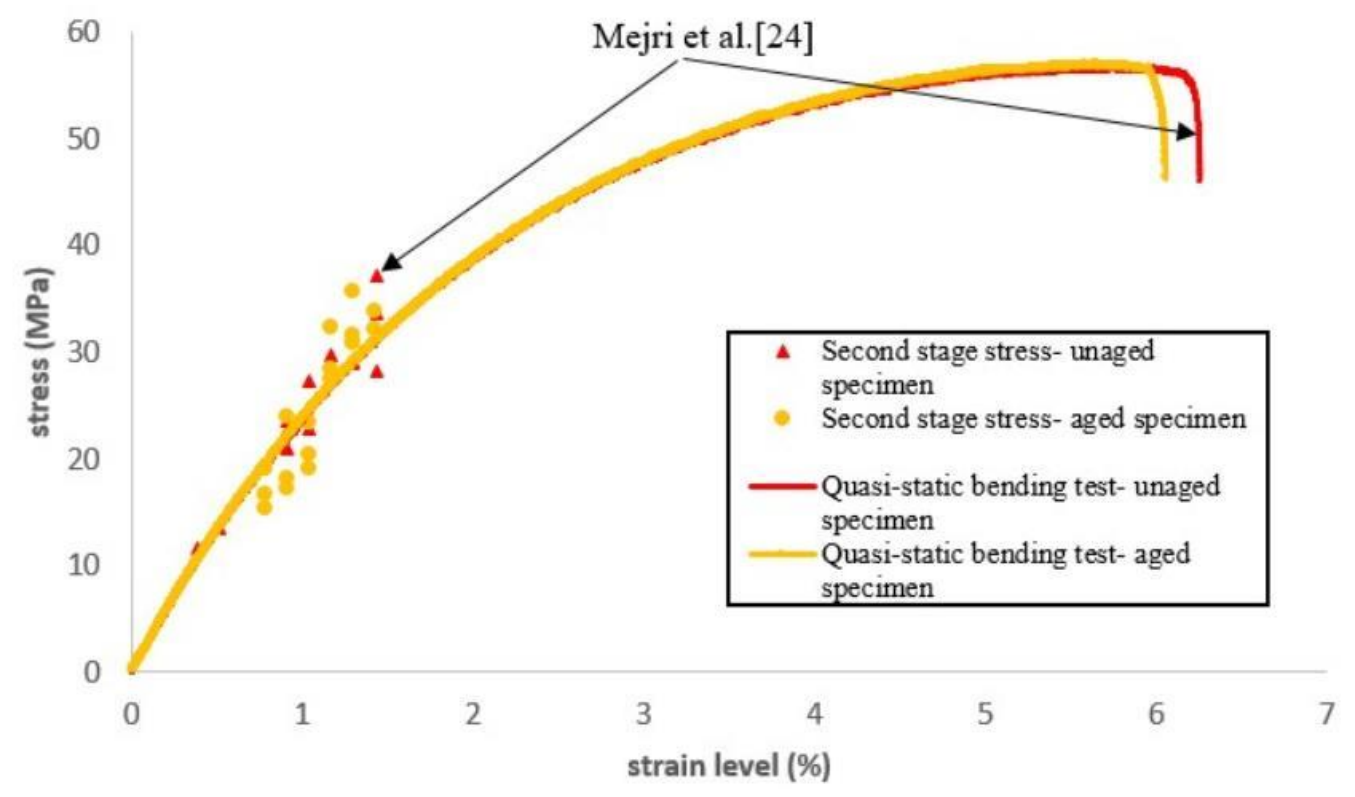

Figure 8: Evolution of second stage mean residual strength of unaged and aged specimens versus the strain level applied

It has been shown in a previous work [24] that self-heating in unaged bending specimens is about $3.3^{\circ} \mathrm{C}$, which can be considered as quite low. Self-heating classically affects polymer materials along fatigue tests and it is directly related to strain level and cyclic frequency applied. Viscous and internal frictional heat dissipation mechanisms convert the major part of mechanical energy supplied into heat [30]. In our tests, a $3.3^{\circ} \mathrm{C}$ self-heating has been measured at rather extreme conditions since we used a $15 \mathrm{~Hz}$ frequency and a 1.43\% strain level (2.2 mm displacement level) [24]. Based on ASTM-D3479, this allowed us to conclude that self-heating does not affect dynamic properties of our composite. Therefore, the fatigue damage of our composite (HDPE/40\%wt of short birch fibers) can be considered as purely mechanical.

As previously demonstrated, hygrothermal aging causes a decrease in fatigue durability of our composite. The possible causes of this decrease are effects of hygrothermal aging on the chemical composition, on the thermal behavior or/and on damage mechanisms of this composite. To investigate the direct cause of this fatigue durability decrease after hygrothermal aging, several other types of tests (FTIR, TGA, SEM) have been performed, as described in the next sections. 


\section{4) FTIR AND TGA TESTS}

\subsection{1) FOURIER TRANSFORM INFRARED SPECTROSCOPY}

After fatigue tests, FT-IR analysis have been performed on broken unaged and aged specimens to investigate differences between their respective chemical compositions.

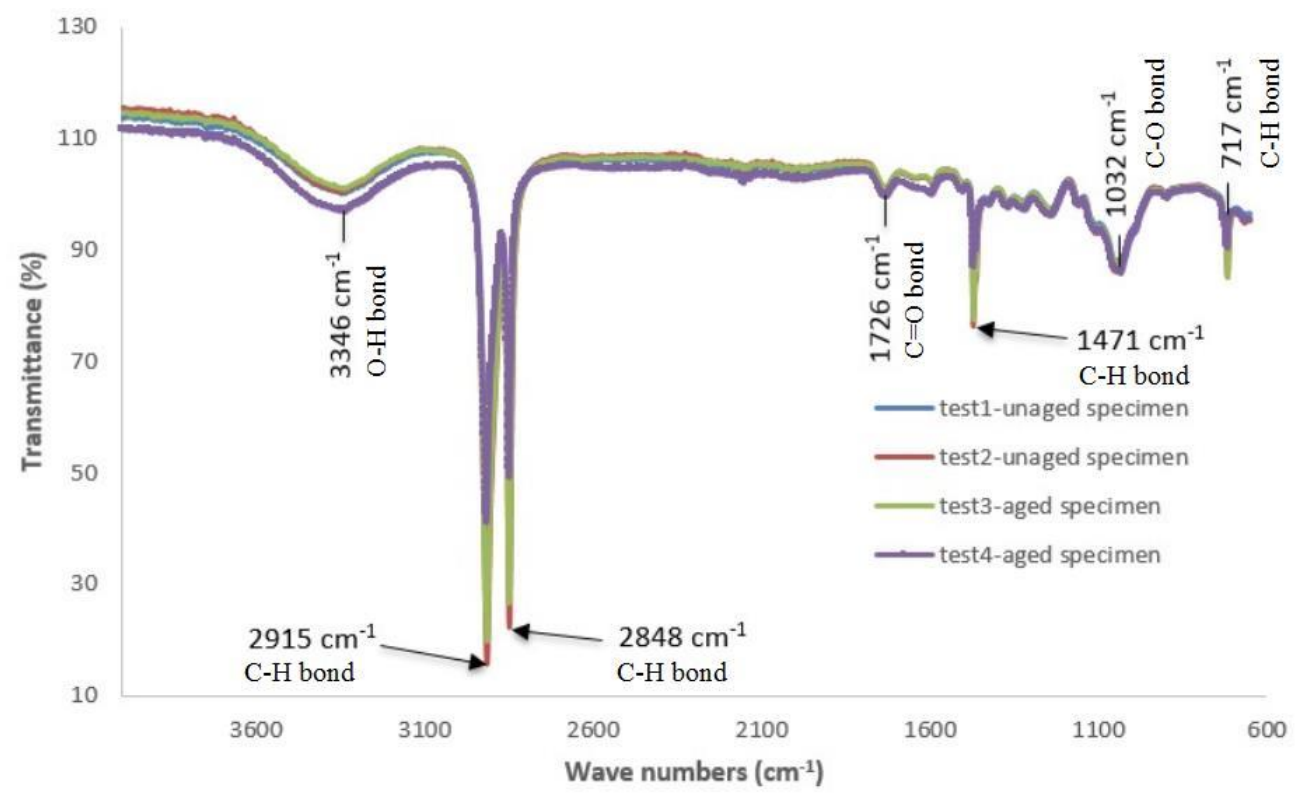

Figure 9: Infrared spectra of unaged and aged HDPE reinforced with $40 \%$ wt of SBF

Figure 9 presents a comparison between FTIR spectra of unaged and aged specimens. Based on literature about wood fibers [31-35], typical absorption bands are identified in the set of spectra presented in Figure 9. Stretching vibrations of $\mathrm{O}-\mathrm{H}, \mathrm{C}-\mathrm{O}$ and $\mathrm{C}=\mathrm{O}$ bonds have been detected respectively at $3346 \mathrm{~cm}^{-1}, 1032$ $\mathrm{cm}^{-1}$ and $1726 \mathrm{~cm}^{-1}$. These $\mathrm{C}-\mathrm{O}$ and $\mathrm{C}=\mathrm{O}$ bonds represent a part of the lignin chemical formula.

Moreover, the bands at $2915 \mathrm{~cm}^{-1}, 2848 \mathrm{~cm}^{-1}, 1471 \mathrm{~cm}^{-1}$ and $717 \mathrm{~cm}^{-1}$ characterize the different types of C$\mathrm{H}$ bonds that are present in wood fibers, MAPE and HDPE matrix. This comparison between spectra of unaged and aged specimens brings about the conclusion that all these spectra feature the same evolution and that there is no significant difference in peaks intensity of typical absorption bands introduced above. Consequently, it appears that hygrothermal aging has not affected the chemical composition of our composite (HDPE reinforced with $40 \%$ wt of short birch fibers).

\subsection{2) THERMOGRAVIMETRIC ANALYSIS}

Fatigue tests have been followed by thermogravimetric analysis (TGA) to investigate the thermal stability of unaged and aged specimens once broken at the end of fatigue tests. 


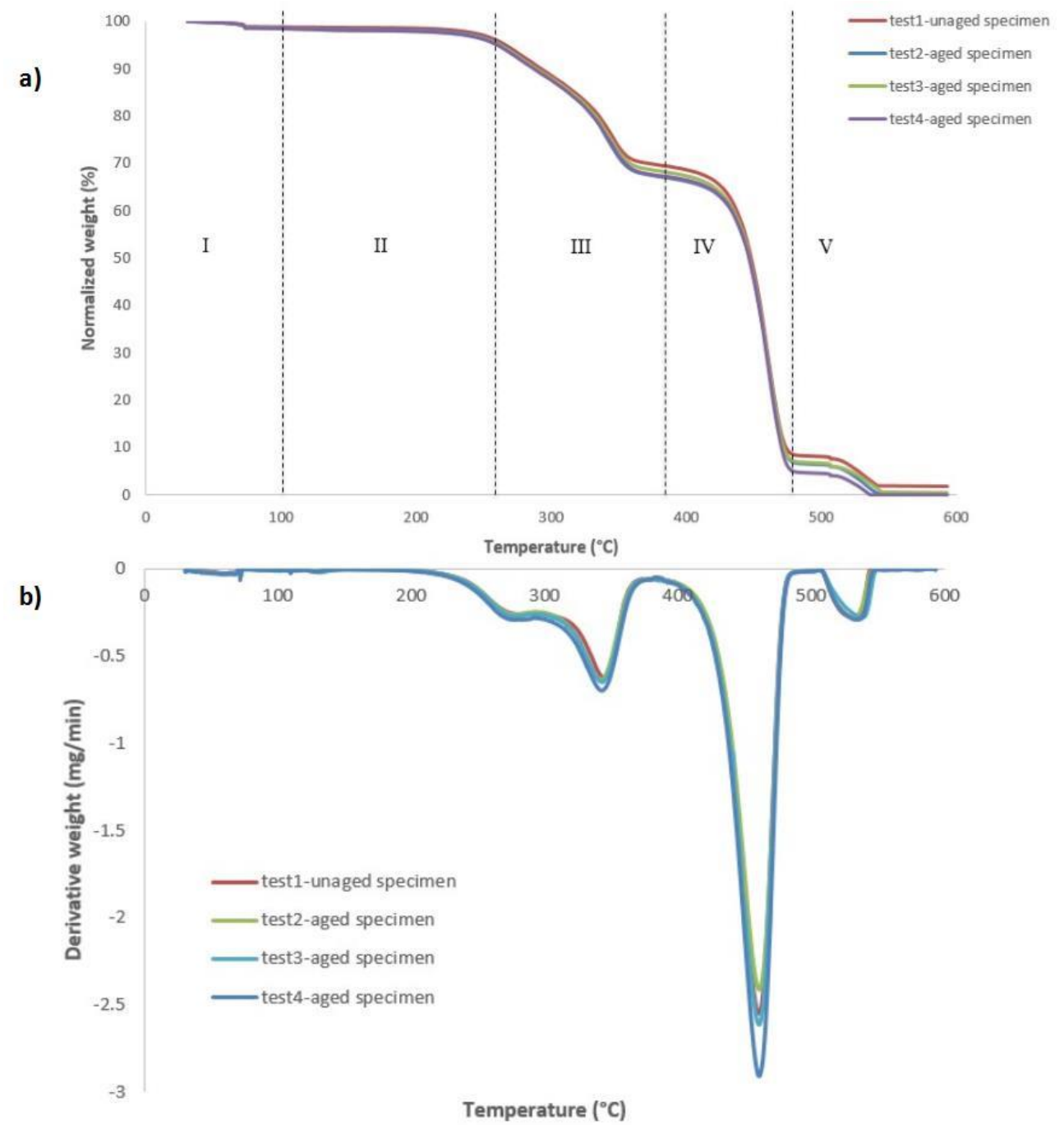

Figure 10: Thermogravimetric analysis curves of unaged and aged specimens: a) TGA curves; b) DTGA curves

Figure 10a illustrates that all TGA curves feature five stages. The first slight initial loss stage can be attributed to remnant water that is present inside birch fibers [36]. Then, the second decomposition stage, which occurs between $100^{\circ} \mathrm{C}$ and $260^{\circ} \mathrm{C}$, characterises the decomposition of hemicellulose that is present inside birch fibers [36]. The third stage, which occurs between $260^{\circ} \mathrm{C}$ and $386^{\circ} \mathrm{C}$, results from the decomposition of cellulose and lignin [35, 36], which represent, with hemicellulose, basic constituents of wood fibers [37, 38]. The fourth stage, which occurs between $386^{\circ} \mathrm{C}$ and $480^{\circ} \mathrm{C}$, represents the decomposition of the HDPE matrix [35]. Finally, the fifth stage, which occurs between $480^{\circ} \mathrm{C}$ and $600^{\circ} \mathrm{C}$, characterises the degradation of char formed along previous decompositions [36]. Moreover, the comparison between unaged and aged specimens TGA curves, shown in Figure 10a, helped us to identify a small difference between their temperature at $5 \%$ of weight loss ( $\left.\mathrm{T}_{5 \%}\right)$. With aged specimens, mean $\mathrm{T}_{5 \%}$ is $261{ }^{\circ} \mathrm{C}$ which is $5^{\circ} \mathrm{C}$ lower if compared with $\mathrm{T}_{5 \%}$ found with unaged specimen $\left(\mathrm{T}_{5 \%}\right.$ is $266^{\circ} \mathrm{C}$ for unaged 
specimen). Based on the work of O.Gil-Castell et al. [36], it appears that this $5^{\circ} \mathrm{C}$ temperature difference between $\mathrm{T}_{5 \%}$ values associated with aged and unaged specimens can be considered as meaningless. Overall, these TGA tests show that TGA curves of unaged and aged specimens are very similar.

Figure 10b shows the first-derivative thermogravimetric analysis (DTGA) curves obtained from Figure 10a. These curves present three peaks that characterize the three most important decompositions stages as described previously, which confirms stage identifications realized from Figure 10a. As shown in Figure $10 \mathrm{~b}$, curves associated with unaged and aged specimens are very similar with the same peak temperature $\left(\mathrm{T}_{\text {peak }}\right)$ for each peak.

From results shown in Figure 10a and Figure 10b, we can conclude that hygrothermal aging has no significant effect on the thermal behavior of our composite (HDPE reinforced with $40 \% \mathrm{wt}$ of short birch fibers). Moreover, since the thermal behavior of such materials is generally related to their chemical composition, FTIR results presented in section 3.4.1 are confirmed by results obtained with thermogravimetric analysis tests.

\section{5) SCANNING ELECTRON MICROSCOPE}

Images of the fractured surfaces of two metallized specimens have been captured using a scanning electron microscope (SEM) as shown in Figure 11 and Figure 12. For these images, fractured unaged and aged bending specimens have been chosen for which the same strain level (1.30\%) had been used in fatigue tests. Since the comparison between SEM images is made for specimens that have been tested at the same strain level, this allows isolating the effect of hygrothermal aging on damage mechanisms without considering the effect of the strain level. 


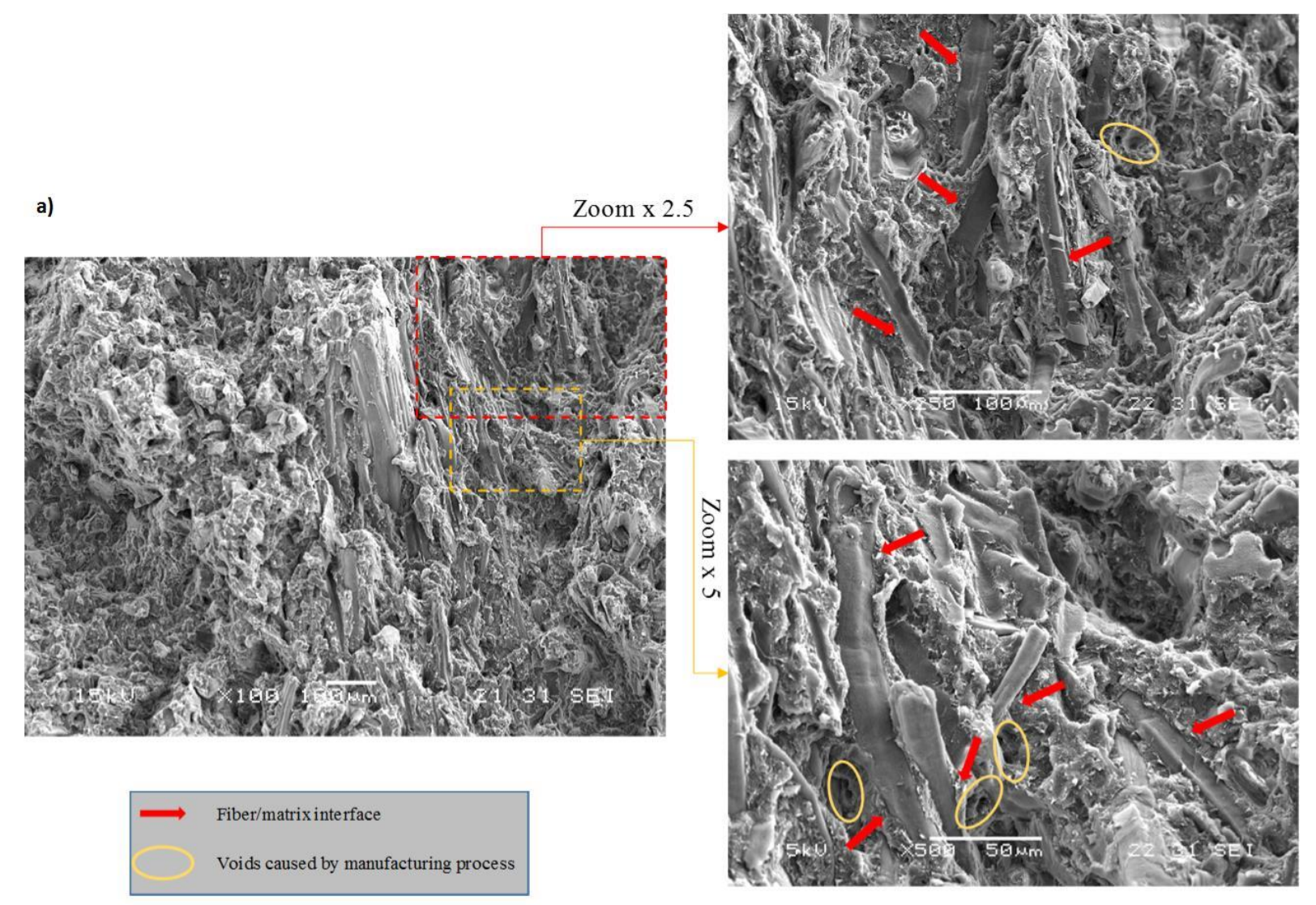

b)

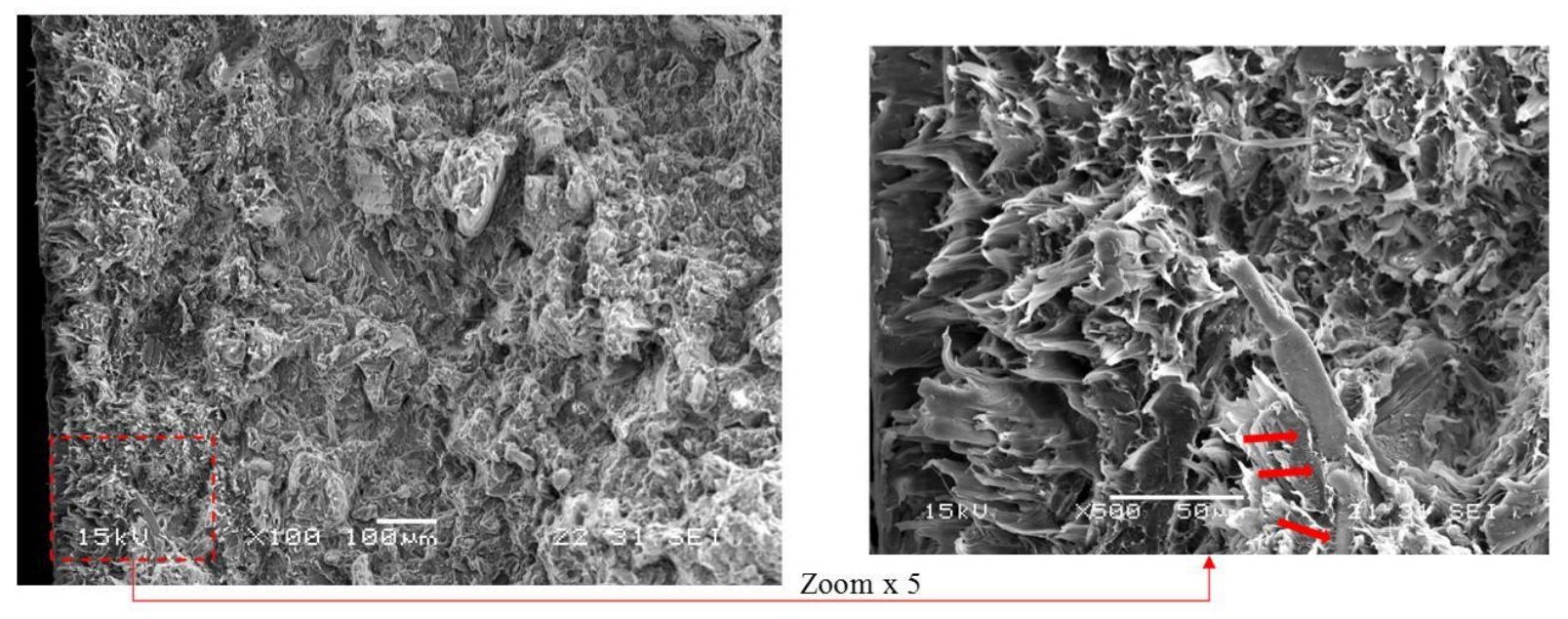

Figure 11: SEM images of fractured surface of an unaged bending specimen made of HDPE and $40 \%$ wt of SBF: a) Image taken in the middle of the fractured surface; b) Image of the fractured surface close to the outer surface of the specimen 
a)

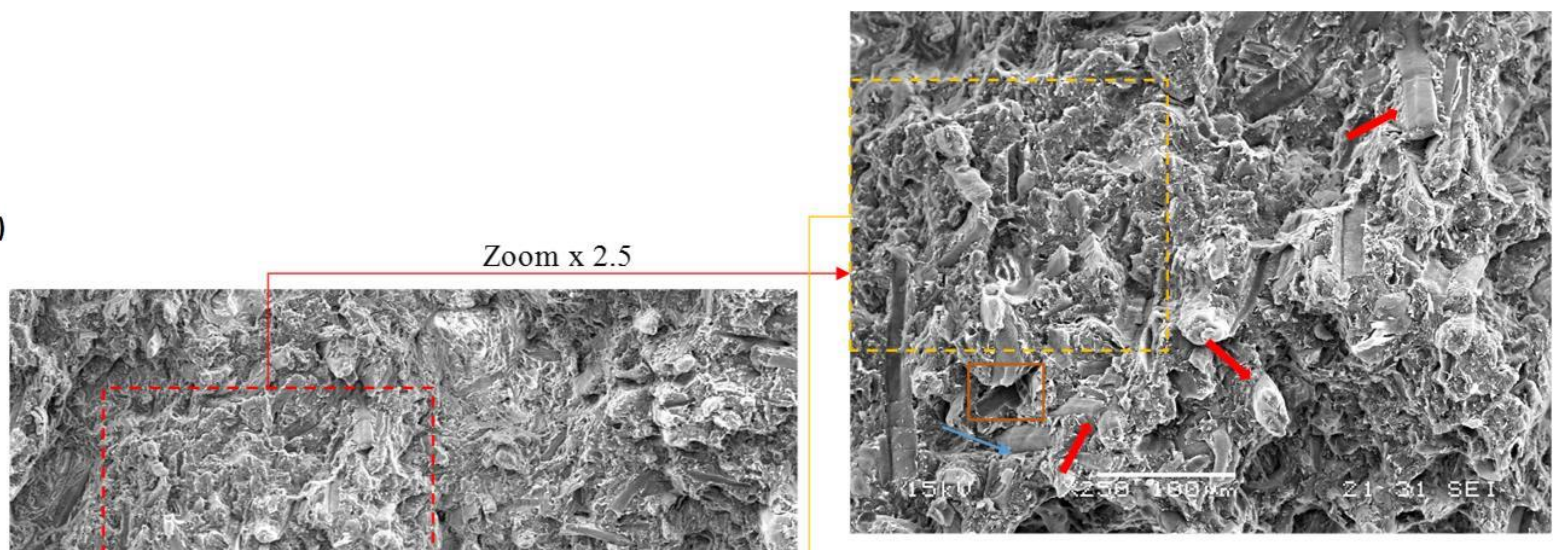

Zoom x 2
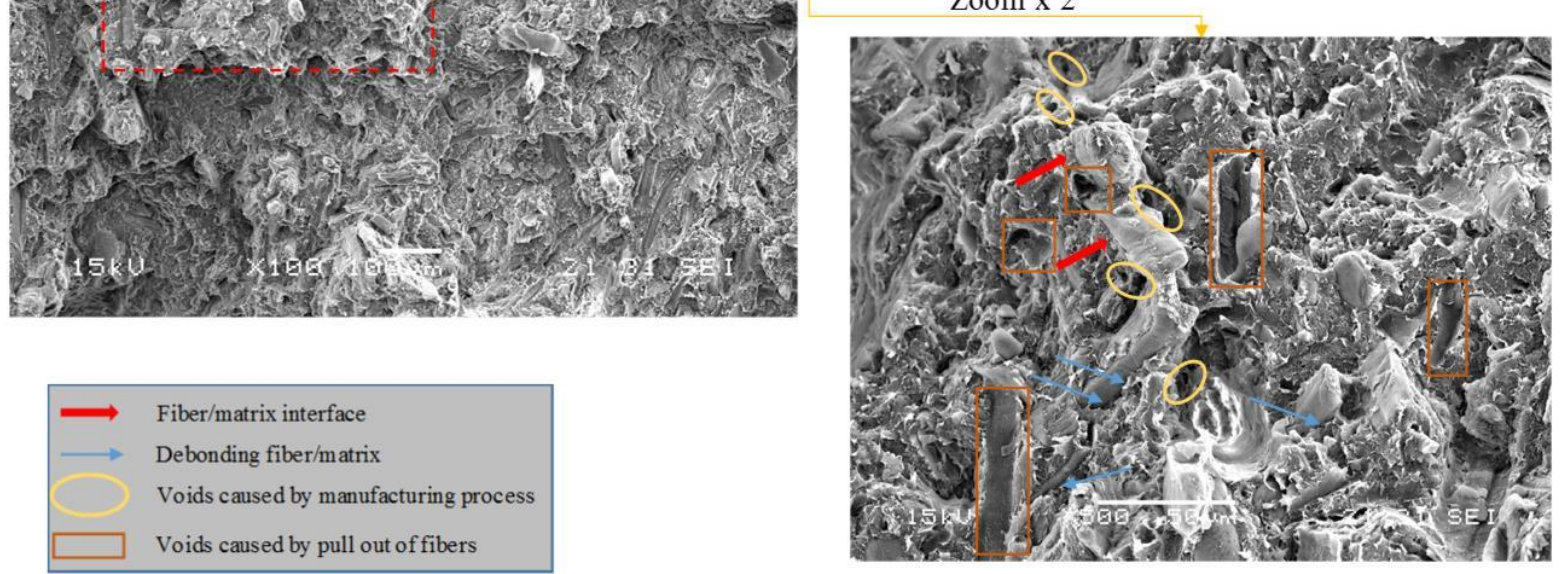

b)

Zoom x 2.5
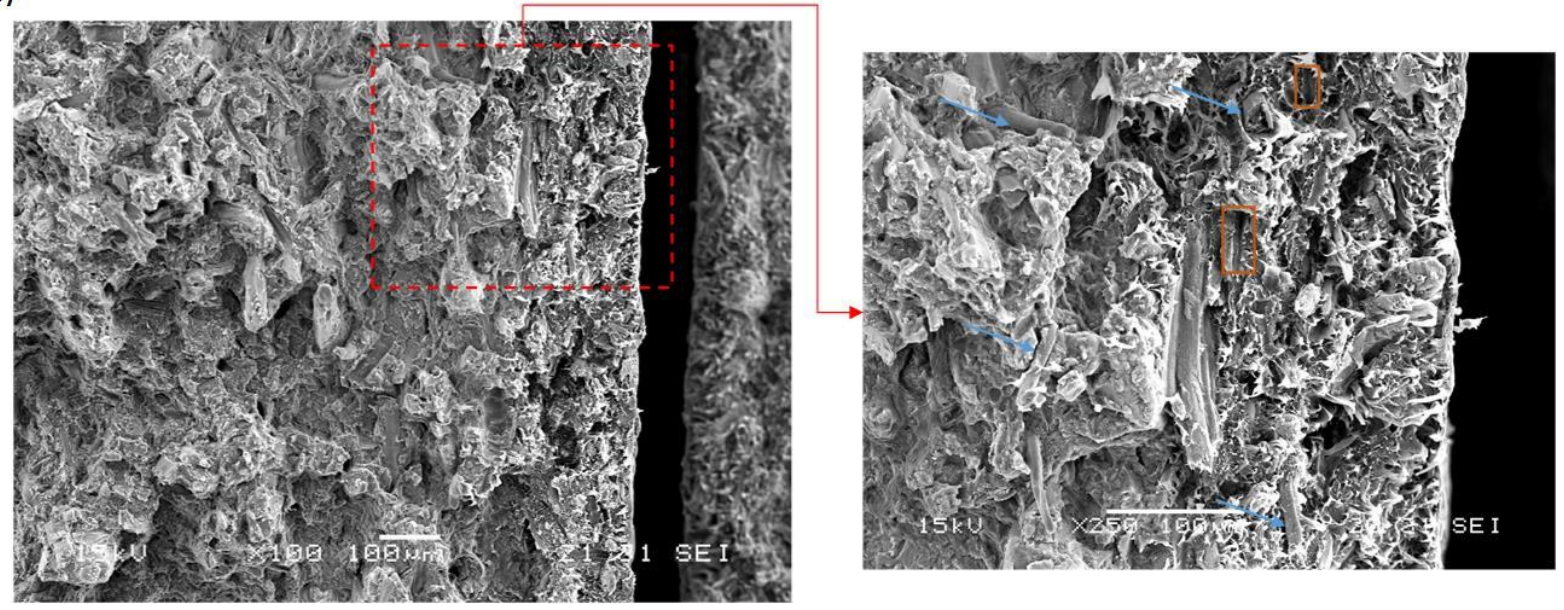

Figure 12: SEM images of fractured surface of an aged bending specimen made of HDPE and 40\%wt of SBF: a) Image taken in the middle of the fractured surface; b) Image of the fractured surface close to the outer surface of the specimen 
Figure 11 and Figure 12 respectively present fractured surfaces of unaged and aged specimens. As indicated in Figure 11 and Figure 12, thick and thin arrows respectively point to undamaged and damaged interfaces (debonding) between birch fibers and the HDPE matrix. Ellipsoidal and rectangular frames respectively indicate voids created during the manufacturing process and after a pull out of fibers. Identifying the type of these voids is based on void geometry: voids generated by the manufacturing process are characterized by a circular section (Figure 1) while voids that result from fibers pull out generally do not feature a regular section due to fibers geometry (Figure 12).

The fractured surface of the unaged specimen (Figure 11a and Figure 11b) shows that interfaces between birch fibers and the matrix have been conserved after fatigue failure. This means that no debonding or/and no pull out of fibers is observed. Moreover, the presence of voids caused by the manufacturing process is detected in Figure 11a. Based on these remarks, we can conclude that fatigue failure of unaged specimen, at a $1.30 \%$ strain level (which corresponds to a $2 \mathrm{~mm}$ displacement level), is caused by the initiation/propagation of micro-cracks in the HDPE matrix and by the fracture of birch fibers. Along water uptake, birch fibers absorb almost all water due to their hydrophilic behavior. This absorption causes the swelling of fibers, which is followed by the creation of micro-cracks in the HDPE matrix and by the reduction of interfacial adhesion matrix/fibers [10,11]. As mentioned in section 3.1, once water saturation is reached, some specimens were dried to eliminate the water absorbed. Drying these specimens makes that the volume of birch fibers decreases until recovering fibers volume before immersion. This decrease of fibers volume negatively affects interfacial adhesion between the fibers and matrix. As shown in Figure 12a and Figure 12b, performing fatigue test after hygrothermal aging induces fibers debonding and voids caused by the pull out of fibers. Based on a comparison between Figure 11 and Figure 12, we can conclude that debonding and pull out of some fibers in aged specimen are caused by the reduction of interfacial adhesion between the fibers and the matrix. Thus, hygrothermal aging affects the damage mechanisms of our composite. The failure of aged specimen at a $1.30 \%$ strain level (which corresponds to a $2 \mathrm{~mm}$ displacement level) is likely to be caused by: initiation/propagation of micro-cracks in the matrix, debonding/pull out of some fibers and fracture of other fibers. In this case, micro-cracks in the matrix are likely to be caused by the fatigue test, by the swelling of fibers during water uptake and by the pressure of water inside voids in the matrix that are induced by the manufacturing process used (identified with ellipses in Figure 11 and Figure 12).

Based on these SEM results and on results presented in section 3.3.1, we can conclude that the changes in damage mechanisms, due to hygothermal aging, can be the direct cause of the decrease of fatigue durability.

\section{4) CONCLUSIONS}

Flexural specimens made of HDPE and $40 \%$ wt of short birch fibers have been aged by immersion in distilled water and by drying after water saturation. Then, flexural quasi-static and fatigue tests have been performed on these aged specimens to investigate the effect of hygrothermal aging on flexural mechanical properties and on flexural fatigue behavior of this natural fiber composite. The influence of hygrothermal 
aging has been studied using comparisons between results presented in this paper and other results presented in a previous work with unaged specimens [24]. Moreover, FT-IR, TGA and SEM were conducted after fatigue tests on broken unaged and aged specimens. The aim of these tests is identifying the direct cause of the fatigue durability decrease observed after hygrothermal aging.

During immersion along hygrothermal aging, the measurement of Young's modulus of these bending specimens shows a $51.21 \%$ decrease in tensile rigidity. Then, if compared to properties of unaged specimens, results of flexural quasi-static tests performed on wet specimens show a $50.81 \%$ decrease of the maximum stress, a $47.24 \%$ decrease of elastic flexural modulus and a $58.07 \%$ increase of maximum strain. Drying wet specimens allows almost completely recovering the initial mechanical properties of unaged specimens. Indeed, the mean maximum stress, mean elastic modulus and mean maximum strain of aged specimens (after immersion in water and drying) are respectively $96.28 \%, 98.82 \%$ and $96.45 \%$ of those of unaged specimens. Moreover, performing X-ray micro computed tomography measurements on unaged specimen shows the presence of low density voids with a spherical geometry, which are caused by the manufacturing process used.

Flexural fatigue tests have been conducted on aged specimens. These tests show that the HCFS of HDPE reinforced with $40 \% \mathrm{wt}$ of short birch fibers corresponds to a $0.78 \%$ strain level, which corresponds to a $1.2 \mathrm{~mm}$ displacement level. Compared with result obtained on unaged specimens [24], we can state that the HCFS of the studied composite decreases after hygrothermal aging. Once the fatigue life evolution assessed, a Weibull statistical analysis has been made on aged specimens. A comparison between characteristic lives of aged and unaged specimens [24] shows that hygrothermal aging decreases the characteristic life of this composite. The gap between the characteristic life trends of unaged and aged specimens increases with the strain level used. Moreover, the evolution of residual strength has been assessed for all strain levels used to characterize fatigue damage of aged specimens. Based on results obtained, we conclude that there are two aspects of residual strength evolution: an evolution featuring three stages for strain levels inducing the failure of specimens before $5 \mathrm{E}+06$ cycles and another evolution, only featuring two stages for strain levels that do not induce the failure of specimens before $5 \mathrm{E}+06$ cycles. Comparing these two aspects of residual strength evolution, it can be stated that the third stage is caused by an initiation and propagation of macro-cracks in aged bending specimens. After assessing these residual strength evolutions, second stage mean residual strengths have been determined, plotted and superposed with corresponding quasi-static bending curves. A comparison between results obtained with aged and unaged [24] specimens shows that hygothermal aging does not affect second stage mean residual strength. Also, it has been observed that controlling strain along fatigue tests can be considered as a valid approach for assessing results based on controlling load along fatigue tests. The stress level can indeed be obtained from results along the second stage of residual strength evolution.

FT-IR and TGA tests on broken unaged and aged specimens respectively show that hygrothermal aging do not affect chemical composition and thermal behavior of the studied composite. A comparison between SEM images of fractured surfaces of unaged and aged specimens, obtained at the same strain 
level, shows debonding and pull out of fibers for aged specimens and not for unaged specimens. Based on that, we can conclude that the fatigue durability decrease observed after hygrothermal aging is caused by an increase of damage mechanisms: with unaged specimen, failure is caused by the initiation/propagation of micro-cracks in the matrix and by the fracture of fibers. For aged specimens, failure is caused by the initiation/propagation of micro-cracks in the matrix and by debonding, pull out and fracture of fibers. In this case, micro-cracks in the matrix are caused by the fatigue test, by the swelling of fibers during water uptake and by the pressure of water inside voids in the matrix that are induced by the manufacturing process used.

Based on results obtained in this work, replacing Nylon by HDPE reinforced with $40 \%$ wt of short birch fibers, in spur gear manufacturing, can be a very interesting avenue to reduce manufacturing cost and oil use. However this remains to be confirmed by further research, such as studying the effect of cyclic hygrothermal and/or ultraviolet aging on the fatigue behavior of this composite.

\section{ACKNOWLEDGMENTS}

This study was carried out as part of a project supported by the Natural Sciences and Engineering Research Council of Canada (NSERC) and UQTR foundation. Birch fibers used were prepared using facilities of the Centre for Research on Lignocellulosic Materials (CRML) in UQTR.

\section{REFERENCES}

1. Biagiotti, J., D. Puglia, and J.M. Kenny, A review on natural fibre-based composites - Part I: Structure, processing and properties of vegetable fibres. Journal of Natural Fibers, 2004. 1(2): p. 37-68.

2. Shah, D.U., Developing plant fibre composites for structural applications by optimising composite parameters: A critical review. Journal of Materials Science, 2013. 48(18): p. 6083-6107.

3. Shah, D.U., Natural fibre composites: Comprehensive Ashby-type materials selection charts. Materials and Design, 2014. 62: p. 21-31.

4. $\mathrm{Ku}, \mathrm{H}$., et al., A review on the tensile properties of natural fiber reinforced polymer composites. Composites Part B: Engineering, 2011. 42(4): p. 856-873.

5. Hu, R.H., M.Y. Sun, and J.K. Lim, Moisture absorption, tensile strength and microstructure evolution of short jute fiber/polylactide composite in hygrothermal environment. Materials and Design, 2010. 31(7): p. 3167-3173.

6. Bledzki, A.K. and O. Faruk, Creep and impact properties of wood fibre-polypropylene composites: influence of temperature and moisture content. Composites Science and Technology, 2004. 64(5): p. 693-700.

7. Xue, Y., et al., Environmental effects on the mechanical and thermomechanical properties of aspen fiber-polypropylene composites. Composites Part B: Engineering, 2007. 38(2): p. 152-158.

8. Assarar, M., et al., Acoustic emission characterization of damage in short hemp-fiber-reinforced polypropylene composites. Polymer Composites, 2016. 37(4): p. 1101-1112.

9. Assarar, M., et al. Mechanical properties analysis of short hemp-fibre/ polypropylene composites: Influence of fibre content and hygrothermal ageing. in ECCM 2012 - Composites at Venice, Proceedings of the 15th European Conference on Composite Materials. 2012.

10. Beg, M.D.H. and K.L. Pickering, Reprocessing of wood fibre reinforced polypropylene composites. Part II: Hygrothermal ageing and its effects. Composites Part A: Applied Science and Manufacturing, 2008. 39(9): p. 1565-1571. 
11. Beg, M.D.H. and K.L. Pickering, Mechanical performance of Kraft fibre reinforced polypropylene composites: Influence of fibre length, fibre beating and hygrothermal ageing. Composites Part A: Applied Science and Manufacturing, 2008. 39(11): p. 1748-1755.

12. Chow, C.P.L., X.S. Xing, and R.K.Y. Li, Moisture absorption studies of sisal fibre reinforced polypropylene composites. Composites Science and Technology, 2007. 67(2): p. 306-313.

13. Le Duigou, A., P. Davies, and C. Baley, Seawater ageing of flax/poly(lactic acid) biocomposites. Polymer Degradation and Stability, 2009. 94(7): p. 1151-1162.

14. Thwe, M.M. and K. Liao, Durability of bamboo-glass fiber reinforced polymer matrix hybrid composites. Composites Science and Technology, 2003. 63(3-4): p. 375-387.

15. Balatinecz, J.J. and B.D. Park, The effects of temperature and moisture exposure on the properties of wood-fiber thermoplastic composites. Journal of Thermoplastic Composite Materials, 1997. 10(5): p. 476-487.

16. Toubal, L., et al., Hygrothermal effect on moisture kinetics and mechanical properties of hemp/polypropylene composite: Experimental and numerical studies. Polymer Composites, 2016. 37(8): p. 2342-2352.

17. Panthapulakkal, S. and M. Sain, Injection-molded short hemp fiber/glass fiber-reinforced polypropylene hybrid composites -mechanical, water absorption and thermal properties. Journal of Applied Polymer Science, 2007. 103(4): p. 2432-2441.

18. Panthapulakkal, S. and M. Sain, Studies on the water absorption properties of short hemp-glass fiber hybrid polypropylene composites. Journal of Composite Materials, 2007. 41(15): p. 18711883.

19. Retegi, A., et al., Effects of hygrothermal ageing on mechanical properties of flax pulps and their polypropylene matrix composites. Journal of Applied Polymer Science, 2006. 102(4): p. 34383445.

20. Yu, T., et al., Water absorption and hygrothermal aging behavior of short ramie fiber reinforced poly(lactic acid) composites. Polymer Composites, 2016.

21. Mijiyawa, F., et al., Formulation and tensile characterization of wood-plastic composites: Polypropylene reinforced by birch and aspen fibers for gear applications. Journal of Thermoplastic Composite Materials, 2014. 28(12): p. 1675-1692.

22. Bravo, A., et al., Development of novel green and biocomposite materials: Tensile and flexural properties and damage analysis using acoustic emission. Materials and Design, 2015. 66(PA): p. 16-28.

23. Bravo, A., et al., Damage Characterization of Bio and Green Polyethylene-Birch Composites under Creep and Cyclic Testing with Multivariable Acoustic Emissions. Materials, 2015. 8(11): p. $7322-7341$.

24. Mejri, M., et al., Fatigue life and residual strength of a short- natural-fiber-reinforced plastic vs Nylon. Composites Part B: Engineering, 2017. 110: p. 429-441.

25. Saoudi, J., et al., Critical thrust force predictions during drilling: Analytical modeling and X-ray tomography quantification. Composite Structures, 2016. 153: p. 886-894.

26. Sodoke, K.F., et al., Fuzzy logic response to Young's modulus characterization of a flax-epoxy natural fiber composite. Materials \& Design, 2016. 89: p. 273-285.

27. Sodoke, F.K., L. Toubal, and L. Laperrière, Hygrothermal effects on fatigue behavior of quasiisotropic flax/epoxy composites using principal component analysis. Journal of Materials Science, 2016. 51(24): p. 10793-10805.

28. Mannan, U.A., M.R. Islam, and R.A. Tarefder, Effects of recycled asphalt pavements on the fatigue life of asphalt under different strain levels and loading frequencies. International Journal of Fatigue, 2015. 78: p. 72-80.

29. Taheri, S., L. Vincent, and J.C. Le-Roux, Classification of metallic alloys for fatigue damage accumulation: A conservative model under strain control for 304 stainless steels. International Journal of Fatigue, 2015. 70: p. 73-84.

30. Shojaei, A.K. and P. Volgers, Fatigue damage assessment of unfilled polymers including selfheating effects. International Journal of Fatigue, 2017. 100: p. 367-376.

31. Migneault, S., et al., Effects of wood fiber surface chemistry on strength of wood-plastic composites. Applied Surface Science, 2015. 343: p. 11-18. 
32. Kumar, A., et al., Hydrophobic treatment of wood fibrous thermal insulator by octadecyltrichlorosilane and its influence on hygric properties and resistance against moulds. Composites Part B: Engineering, 2016. 106: p. 285-293.

33. El Boustani, M., et al., Solvent-free acetylation of lignocellulosic fibers at room temperature: Effect on fiber structure and surface properties. Journal of Applied Polymer Science, 2015. 132(29).

34. Bouafif, H., et al., Analysis of among-species variability in wood fiber surface using DRIFTS and XPS: Effects on esterification efficiency. Journal of Wood Chemistry and Technology, 2008. 28(4): p. 296-315.

35. Awal, A., S.B. Ghosh, and M. Sain, Thermal properties and spectral characterization of wood pulp reinforced bio-composite fibers. Journal of Thermal Analysis and Calorimetry, 2010. 99(2): p. 695-701.

36. Gil-Castell, O., et al., Impact of hydrothermal ageing on the thermal stability, morphology and viscoelastic performance of PLA/sisal biocomposites. Polymer Degradation and Stability, 2016. 132: p. 87-96.

37. Kärenlampi, P.P., P. Tynjälä, and P. Ström, Molecular fatigue in steamed wood. International Journal of Fatigue, 2003. 25(6): p. 489-497.

38. Kärenlampi, P.P., P. Tynjälä, and P. Ström, Off-axis fatigue loading of steamed wood. International Journal of Fatigue, 2002. 24(12): p. 1235-1242. 
Figure 13: X-ray tomography of an unaged bending specimen made of HDPE and 40\%wt of SBF: a) CAD model of bending specimen; $\mathrm{b})$ two scans in $(\mathrm{y}, \mathrm{z})$ plane; $\mathrm{c})$ two scans in $(\mathrm{x}, \mathrm{y})$ plane; d) two scans in $(\mathrm{x}, \mathrm{z})$ plane

Figure 14: Hygrothermal aging of specimens a) Location of bending specimens in the thermal bath; $b$ ) Location of bending specimens in the MTS environmental chamber

Figure 15: MTS fatigue machine setup with a CCD camera

Figure 16: a) Water uptake of immersed specimens versus square root of immersion time; b) Elastic tensile modulus of immersed specimens versus square root of immersion time

Figure 17: Bending stress-strain curves of aged HDPE/40\%wt of SBF superposed with results obtained with wet and unaged specimens [24]

Figure 18: Fatigue durability of aged and unaged [24] HDPE reinforced with 40\%wt of SBF: a) $\varepsilon$-N curves; b) Evolutions of characteristic life with the strain level applied

Figure 19: Evolution of residual strength of aged specimens versus the number of fatigue cycles: a) At a $1.17 \%$ strain level ( $1.8 \mathrm{~mm}$ displacement level); b) At a $0.78 \%$ strain level (1.2 $\mathrm{mm}$ displacement level)

Figure 20: Evolution of second stage mean residual strength of unaged and aged specimens versus the strain level applied

Figure 21: Infrared spectra of unaged and aged HDPE reinforced with $40 \%$ wt of SBF

Figure 22: Thermogravimetric analysis curves of unaged and aged specimens: a) TGA curves; b) DTGA curves

Figure 23: SEM images of fractured surface of an unaged bending specimen made of HDPE and 40\%wt of SBF: a) Image taken in the middle of the fractured surface; b) Image of the fractured surface close to the outer surface of the specimen

Figure 24: SEM images of fractured surface of an aged bending specimen made of HDPE and $40 \%$ wt of SBF: a) Image taken in the middle of the fractured surface; b) Image of the fractured surface close to the outer surface of the specimen 
Table 2: Bending mechanical properties of unaged and aged specimens made of HDPE $/ 40 \% \mathrm{wt}$ of SBF 